\title{
INFECCIONES INTRAHOSPITALARIAS EN EL ESTUDIANTE DE MEDICINA
}

\author{
INTRAHOSPITAL INFECTIONS IN THE MEDICINE STUDENT \\ Joan A. Loayza-Castro ${ }^{1,2}$, Josué R. Sánchez-Cruz¹, Athenas P. Ortiz-Melgar ${ }^{1}$
}

\begin{abstract}
Sr. Editor
Las enfermedades asociadas a la atención en el sector salud es una problemática que no solo implica a los pacientes que ingresan al servicio, si no al personal y a los estudiantes que llevan a cabo sus prácticas en las diferentes instituciones.

Las infecciones intrahospitalarias están definidas como: “Enfermedades localizadas o sistémicas que resultan de una reacción adversa consecuente a la exposición a un agente infeccioso o a sus toxinas, sin evidencia que la infección estuviera presente o en periodo de incubación en el momento de la atención"(1). La falta de conocimientos por parte del personal y estudiantes de las ciencias de la salud que están en contacto con los pacientes, además de la realización de prácticas sanitarias sin tomar en cuenta las medidas de bioseguridad pertinentes son los principales motivos para contraer una infección nosocomial.
\end{abstract}

Unas de las principales fuentes de contaminación nosocomial son las manos. La Organización Mundial de la Salud (OMS) indica que el lavado de manos debe ser realizada obligatoriamente en cinco momentos de la atención al paciente: a) antes de tocar al paciente, b) antes de realizar tarea aséptica, c) después del riesgo de exposición a líquidos corporales, d) después de tocar al paciente y e) después de contacto con el entorno del paciente ${ }^{(2)}$. En el Perú, se ha encontrado que el $70 \%$ del personal de salud no cumple con la adherencia al lavado de manos, además, un estudio hallado muestra que, en un hospital de tercer nivel de atención en Lima, el 91,9\% de los estetoscopios está contaminado y los médicos poseen poca información sobre la importancia de la limpieza de estos. En otro estudio se encontró que el 95\% de los teléfonos móviles en un hospital de tercer nivel presentó crecimiento bacteriano, la mayoría Staphylococcus aureus, seguido de Streptococcus spp, enterobacterias y Pseudomona aeruginosa ${ }^{(3)}$.

En cuanto a los conocimientos y actitudes del interno de medicina frente a las medidas de bioseguridad, en un estudio realizado en la ciudad de Arequipa se encontró que el $40 \%$ de internos que tienen un alto conocimiento sobre las medidas de bioseguridad tienen una inadecuada actitud frente a esta. El $36.40 \%$ de internos tiene un conocimiento bajo y una actitud inadecuada frente al manejo de residuos contaminados ${ }^{(4)}$. Hay evidencia científica sobre esta problemática que se viene desarrollando a nivel global, en la cual nuestro país no es ajeno a esta realidad y está incrementando su prevalencia.

Como estudiantes de medicina y con respaldo de los médicos, enfermeras y personal de salud, llegamos a la conclusión que es necesario la implementación de talleres, cursos, charlas y capacitaciones que estén en dirección a no solo el buen conocimiento sobre la bioseguridad, sino también a las actitudes de nosotros frente a este tema tan importante, así como normativas que velen por la seguridad de los estudiantes de medicina que están en contacto con los pacientes día a día durante el desarrollo de sus prácticas; con esto dejamos carta abierta a que se tenga en cuenta el tema de bioseguridad como tema a investigar en futuras publicaciones.

1 Sociedad Científica de Estudiantes de Medicina de la Universidad Ricardo Palma (SOCEMURP), Lima-Perú.

2 International Federation of Medical Students Associations Perú (IFMSA Perú), Lima-Perú.

Citar como: Joan A. Loayza-Castro, Josué R. Sánchez-Cruz, Athenas P. Ortiz-Melgar. Infecciones intrahospitalarias en el estudiante de medicina. Rev. Fac. Med. Hum. Enero 2020; 20(1):171-172. DOI 10.25176/RFMH.v20i1.2703 
Contribuciones de autoría: Los autores participaron en la generación, recolección de información, redacción y versión final del artículo original.

Financiamiento: Autofinanciado.

\section{Correspondencia: Joan A. Loayza Castro.}

Dirección: Av. Benavides 5440, Surco, Lima-Perú.

Teléfono: 946558954

Correo: loayzacastrojoan@gmail.com
Conflicto de interés: Los autores declaran no tener conflictos de interés en la publicación de este artículo.

Recibido: 24 de setiembre del 2019

Aprobado: 16 de diciembre del 2019

\section{REFERENCIAS BIBLIOGRÁFICAS}

1. Guevara A. Tedesco-Maiullari R. Conocimiento sobre infecciones asociadas a la atención de la salud en estudiantes de bionalásis. Acta Bioquim Clin Latinoam. 2019; 53(!): 53 - 61.

2. Polacco M, Shinkunas L, Perencevich E, Kaldjian L, Reisinger H. See one, do one, teach one: Hand hygiene attitudes among medical students, interns, and faculty. American Journal of Infection Control. 2015;43(2):159-161.

3. Peña Uriarte X. Vera Escudero C. Vera Escudero V. Cumplimiento de higiene de manos, celulares y estetoscopios en personal médico, internos y externos en las rondas médicas del servicio de medicina interna, enfermedades infecciosas y tropicales, emergencia y cuidados intensivos generales en un hospital de tercer nivel de Lima - Perú. Tesis para la obtención de Título Profesional de Medico Cirujano, Facultad de Medicina de la Universidad Peruana Cayetano Heredia, 2019.

4. Huaracallo Laura MP. Relación entre conocimientos y actitudes sobre medidas de bioseguridad en internos de medicina de Hospital estatal de Arequipa, 2019. Tesis para optar el Titulo Profesional de Médico Cirujano, Facultad de Medicina de la Universidad Nacional de San Agustín de Arequipa, 2019.

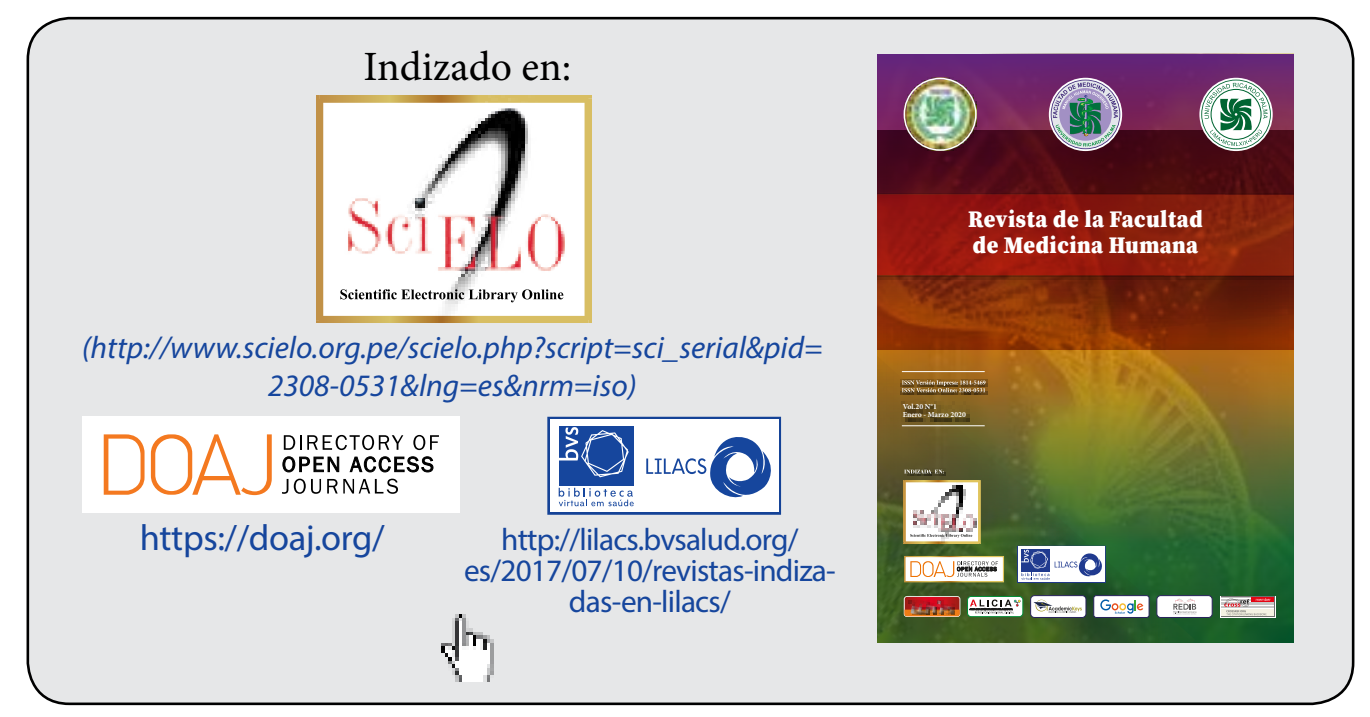

